\title{
Fluid Flow and Mixing Phenomena in the Ladle Stirred by Argon through Multi-Tuyere
}

\author{
Miao-Yong ZHU, Takeo INOMOTO, ${ }^{1)}$ Ikuo SAWADA ${ }^{2)}$ and Tse-Chiang HSIAO
}

Ferrous Metallurgy Department, Northeastern University, Shenyang, P. R. of China.

1) Process Technology Research Laboratories, Nippon Steel Corporation, Shintomi, Futtsu, Chiba-ken, 293 Japan.

2) Advanced Materials and Technology Research Laboratories, Nippon Steel Corporation, Ida, Nakahara-ku, Kawasaki, Kanagawa-ken, 211 Japan.

(Received on October 21, 1994; accepted in final form on January 27, 1995)

\begin{abstract}
Water model experiments and the numerical solution of a mathematical model with three dimensions have been conducted to investigate the flow pattern and mixing phenomena in argon-stirred ladles with six types of tuyere arrangement. It was found that the arrangement of tuyeres has a great effect on the flow patterns and mixing in the ladle, a placement of single tuyere at off-centric position gave the shortest mixing time whereas double tuyeres opposite placed at half radii was found to be the best arrangement considering the aspects of blowing, mixing, inclusion flotation and splashing. An empirical correlation for mixing time in the ladle considering the number of tuyeres was proposed. The predicted and measured results showed quantitatively good agreements.
\end{abstract}

KEY WORDS: physical modeling; mathematical modeling; fluid flow; mixing; multi-tuyere.

\section{Introduction}

The ladle refining by argon stirring has received considerable attention due to its many advantages such as homogenization of temperature and chemical composition of molten steel, acceleration of the metal/slag reaction, and removal of nonmetallic inclusion; on the other hand, its capital cost is much lower. Due to its wide application in iron and steelmaking industries, extensive studies concerning important phenomena in gas-stirred ladles with single tuyere have been done in the past over two decades, which can be classified as follows:

(1) to study the structure of the plume such as the size of bubbles, the rising velocity of liquid and bubbles, the distribution of void fraction and bubble frequency, and the shape of the plume, etc. ${ }^{1-7)}$

(2) to study the mean liquid flow pattern with physical modeling and mathematical modelling ${ }^{8-21)}$

(3) to study the mixing and mass transfer phenomena $22-32)$

In spite of the above studies, still many opportunities exist for improving the performance of metallurgical operation by paying attention to these flows. Recently, for production of high quality steel, the gentle blowing technique in the ladle with multi-tuyere has been put into practice. However, the detailed information regarding the behavior of fluid flow and the mixing nature which depend on the arrangement of tuyeres and gas flowrate is still not clear, and very few studies ${ }^{19)}$ on this aspect has been reported till today.

The purpose of the present work was to investigate experimentally and numerically the behavior of fluid flow and mixing phenomena in the argon-stirred ladle with multi-tuyere. The effects of different arrangement of tuyeres on the flow patterns and mixing were studied and a proper arrangement of tuyeres for the gentle and rapid mixing has been proposed.

\section{Experimental}

\subsection{Similarity Considerations}

In the gas-stirred system, the fluid flow and mixing of the bath are caused by momentum transfer between blown gas and liquid. The flowrate of injected gas in the model can be determined by the modified Froude number which is defined by

$$
N_{F r}^{\prime}=\rho_{g} u^{2} /\left(\rho_{l} g H\right)
$$

where $H$ is the height of the bath.

For $N$ tuyeres with equal inner diameter $d$, the superficial velocity $u$ is given by

$$
u=4 Q /\left(\pi d^{2} N\right)
$$

where $Q$ is the gas flowrate.

Substitute Eq. (2) into Eq. (1), we obtain

$$
N_{F r}^{\prime}=1.621 \rho_{g} Q^{2} /\left(\rho_{l} N^{2} d^{4} g H\right)
$$

If we assume both of the full scale ladle and water model using the same number of tuyeres the following equation can be used to determine the gas flowrate in the model.

$$
\left(\frac{Q_{1}}{Q_{2}}\right)^{2}=\frac{\rho_{g 2}}{\rho_{g 1}} \cdot \frac{\rho_{l 1}}{\rho_{l 2}} \cdot\left(\frac{\overline{d_{1}}}{d_{2}}\right)^{4} \cdot\left(\frac{H_{1}}{H_{2}}\right)
$$


where the subscripts 1 and 2 stand for model and full scale ladle, respectively. The main variables involved in the present consideration are listed in Table 1.

\subsection{Experimental Set-up}

The experimental set-up is shown in Fig. 1. The system consists of a cylindrical plexiglass vessel containing tap water at room temperature. Argon gas was injected into the bath through nozzles which are located at the replaceable bottom of the vessel. Different configurations of the tuyeres used in the present study is shown in Fig. 2. For each configuration, three points at the surface of the bath were selected as tracer adding position.

To monitor local conductivity of water after the addition of $20 \% \mathrm{NaCl}$, an electrical conductivity probe was placed at $20 \mathrm{~mm}$ above the bottom and from the sidewall in the ladle. The output signal of electrical conductivity meter was recorded by a personal computer combined with $\mathrm{A} / \mathrm{D}$ interface on an amplifier. Mixing time

Table 1. The main variable associated with present studies.

\begin{tabular}{lcc}
\hline & $\begin{array}{c}\text { Full scale ladle } \\
(350 \mathrm{t} / \mathrm{ch})\end{array}$ & $\begin{array}{c}\text { Water model } \\
(1: 10)\end{array}$ \\
\hline Diameter $(\mathrm{m})$ & 4.0 & 0.40 \\
Height $(\mathrm{m})$ & 4.0 & 0.40 \\
Diameter of tuyeres $(\mathrm{mm})$ & 10.0 & 3.0 \\
Argon flowrate $(\mathrm{N} l / \mathrm{min})$ & $350-800$ & $4-8$ \\
Density of liquid $\left(\mathrm{kg} / \mathrm{m}^{3}\right)$ & 7000 & 1000 \\
\hline
\end{tabular}



Fig. 1. Representation of experimental set-up.



Case A

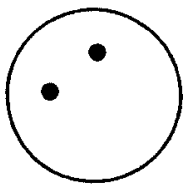

Case D

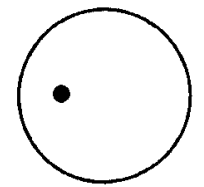

Case B

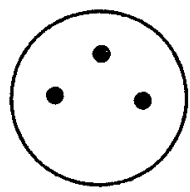

Case E

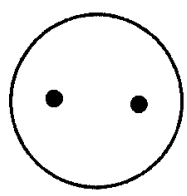

Case C

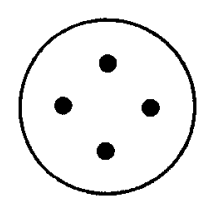

Case $\mathrm{F}$
Fig. 2. Six types of tuyeres arrangement in the ladle. is defined as the time beyond which the changes of conductivity are less than $5 \%$ of the steady state. For each case more than 5 times measurements were performed, and the mean value was taken as mixing time. It was found that individual mixing time fell within $10 \%$ of the mean values.

In order to visualize the flow pattern in argon-stirred model ladle, alumina particles of $0.2 \mathrm{~mm}$ diameter and density close to water were used.

\section{Mathematical Model}

\subsection{Mathematical Formulation}

The fluid flow, turbulent properties and tracer dispersion in the ladle can be described by continuity equation, Navier-Stokes equations, turbulent model and mass conservation equation, which can be written as follows:

Continuity equation

$$
\frac{\partial\left(\rho u_{i}\right)}{\partial x_{i}}=0
$$

Momentum equation

$\frac{\partial\left(\rho u_{i} u_{j}\right)}{\partial x_{j}}=-\frac{\partial p}{\partial x_{i}}+\frac{\partial}{\partial x_{j}}\left[\mu_{\mathrm{eff}}\left(\frac{\partial u_{i}}{\partial x_{j}}+\frac{\partial u_{j}}{\partial x_{i}}\right)\right]+F_{i}$

where $F_{i}$ the body force is $\alpha \rho_{l} g_{i}$ in the case of gas blowing in the ladle.

The effective viscosity $\mu_{\text {eff }}$ showing in Eq. (6) was determined by solving the $k-\varepsilon$ turbulent model ${ }^{33)}$ which can be represented by the following:

$$
\begin{aligned}
& \frac{\partial}{\partial x_{i}}\left(\rho u_{i} k-\frac{\mu_{\text {eff }}}{\sigma_{k}} \cdot \frac{\partial k}{\partial x_{i}}\right)=G_{k}-\rho \varepsilon \\
& \frac{\partial}{\partial x_{i}}\left(\rho u_{i} \varepsilon-\frac{\mu_{\text {eff }}}{\sigma_{\varepsilon}} \cdot \frac{\partial \varepsilon}{\partial x_{i}}\right)=\frac{\left(C_{1} \varepsilon G_{k}-C_{2} \rho \varepsilon^{2}\right)}{k}
\end{aligned}
$$

where $G_{k}$, the generation term, is given by

$$
G_{k}=\mu_{t} \frac{\partial u_{j}}{\partial x_{i}}\left(\frac{\partial u_{i}}{\partial x_{j}}+\frac{\partial u_{j}}{\partial x_{i}}\right)
$$

The auxiliary relationships are:

$$
\mu_{\mathrm{eff}}=\mu_{l}+\mu_{t}
$$

where

$$
\mu_{t}=\rho C_{\mu} k^{2} / \varepsilon
$$

The constants used in present study were recommended by Launder and Spalding. ${ }^{33)}$

For the tracer dispersion in the vessel, it was considered as the same properties of the bulk liquid and added at time zero. The governing differential equation for conservation of mass is represented by

$$
\frac{\partial(\rho C)}{\partial t}+\frac{\partial\left(\rho u_{i} C\right)}{\partial x_{i}}=\frac{\partial}{\partial x_{i}}\left(\rho \Gamma_{\text {eff }} \frac{\partial C}{\partial x_{i}}\right)
$$

where $\Gamma_{\text {eff }}$ the effective mass diffusion coefficient, which is given by

$$
\Gamma_{\text {eff }}=\frac{\mu_{l}}{S_{c}}+\frac{\mu_{t}^{-}}{S_{c t}}
$$


where $S_{c}$ and $S_{c t}$ are laminar and turbulent Schmidt number respectively. In present study, $S_{c t}$ and $S_{c}$ were considered to be unity and 800 respectively.

\subsection{Treatment of the Plume}

In the present study, the gas voidage of the plume was determined by an experimental correlation proposed by Castillejos and Brimacombe, ${ }^{57}$ which has been well used for three-dimensional fluid flow simulation in the gasstirred ladle. $^{34)}$

The density of the plume can be obtained by

$$
\rho=\alpha \rho_{g}+(1-\alpha) \rho_{l}
$$

\subsection{Boundary Conditions}

The velocities parallel to the walls and the turbulence quantities near to the wall nodes were calculated by using wall function. ${ }^{33)}$ At the free suface, the vertical velocity and normal gradients of the other variables were set to be zero. At the solid wall, free slip boundary condition was set for velocity, pressure and concentration.

\subsection{Numerical Solution Procedure}

The differential equations have been discretized by using a control-volume method. A hybrid differencing scheme was adopted to approximate the convection and diffusion terms, whereas for the transient term in mass conservation equation, an implicit differencing scheme was used. Each difference equation was solved by using tridiagonal matrix algorithm. The system of equations was solved with SIMPLE algorithm (Semi-Implicit Method for solving Pressure-Linked Equations). The program employed was developed by present author for simulating three-dimensional transport processes in metallurgical reactions. ${ }^{34)}$ The domain was divided into curvilinear grids of $20 \times 20 \times 20$ in the three directions. All the computations were performed on Sun-Sparc 10. About 300-700 iterations were needed to reach converged values of velocity fields, which takes about $2-4 \mathrm{~h}$.

\section{Results and Discussion}

\subsection{The Characteristics of Fluid Flow}

4.1.1. Flow Patterns in the Ladle with Single Tuyere

Figures 3 and $\mathbf{5}$ provided the predicted and visualized flow patterns at the main vertical plane in the ladle in Case A and Case B, respectively, and Figs. 4 and $\mathbf{6}$ show the flow pattern at the top horizontal plane for these two cases, respectively. It can be seen that two axisymmetric recirculations are formed in the bath and the velocity in the plume zone and near the sidewalls and free surface are relatively large and there is almost no angular velocity in Case A. As contrasted with center blowing, it can be found in Case B that the velocity in plume zone and near the sidewall decreased, however the angular velocity which will have a great effect on the mixing in the ladle and the velocity near the bottom increased significantly (as seen in Figs. 5 and 6).

4.1.2. Flow Patterns in the Ladle with Multi-tuyere

Figures 7 to 10 show the predicted and visualized flow patterns at the main vertical plane when argon gas was injected through two, three and four tuyeres respectively.



(b) visualized

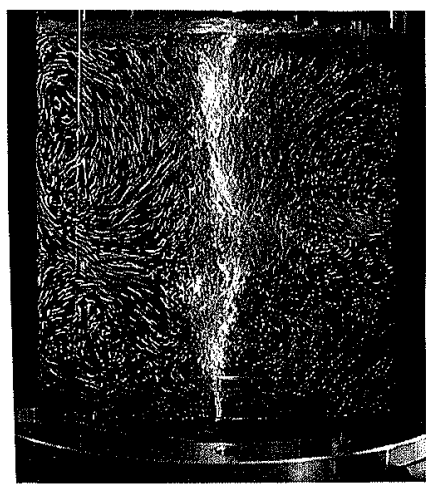

Fig. 3. Predicted and visualized flow patterns as single tuyere was placed at center in the ladle. (Case A, argon flowrate $6 \mathrm{~N} / / \mathrm{min}$ )



Fig. 4. Predicted flow pattern at free surface in the ladle. (Case A, argon flowrate $6 \mathrm{~N} l / \mathrm{min}$ )

It can been seen from the figures that the configuration of tuyeres has a great effect on flow patterns in the ladle, which directly influences the mixing phenomena. 


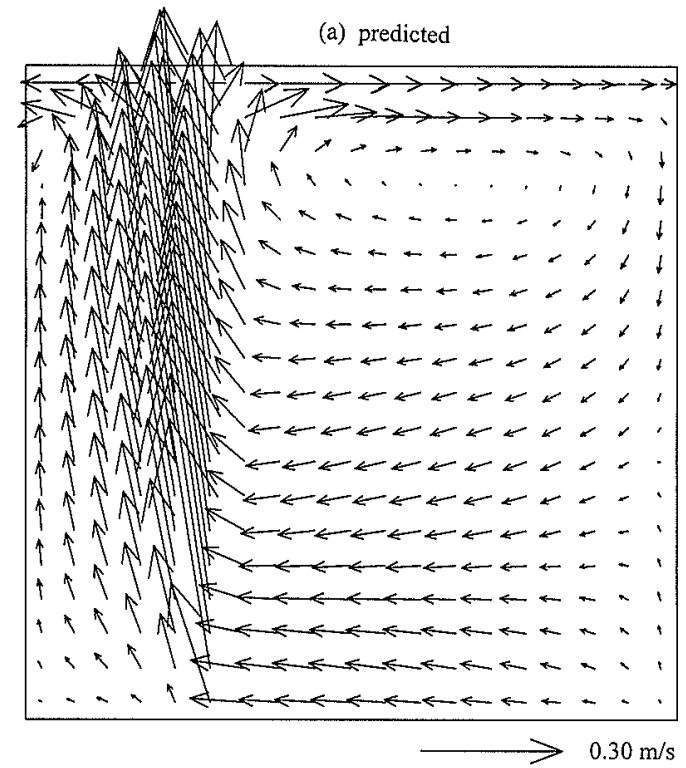

(b) visualized

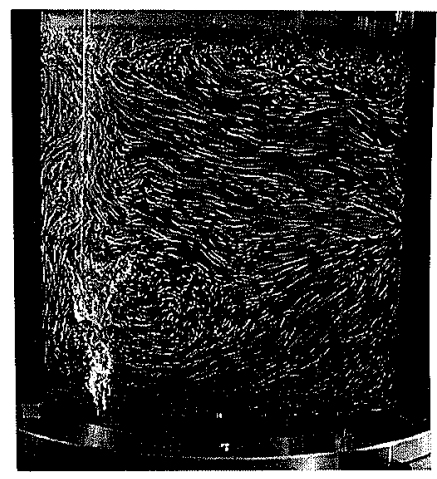

Fig. 5. Predicted and visualized flow patterns as single tuyere was place at half radius in the ladle. (Case B, argon flowrate $6 \mathrm{~N} / / \mathrm{min}$ )

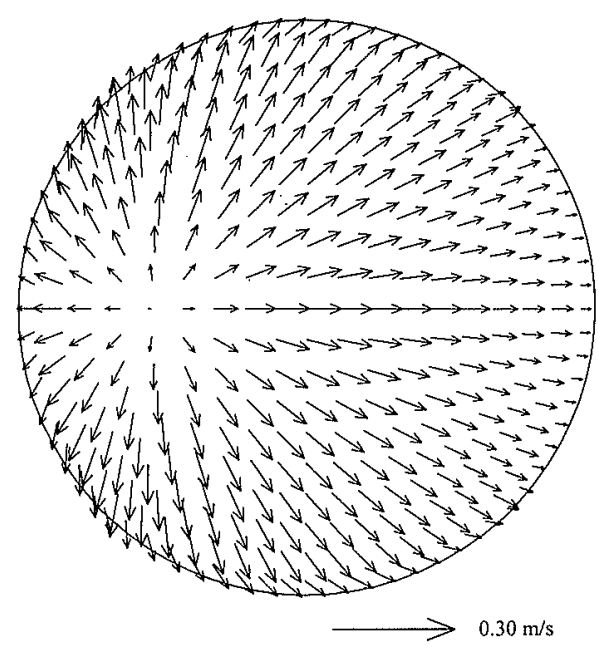

Fig. 6. Predicted flow pattern at free surface in the ladle. (Case $\mathrm{B}$, argon flowrate $6 \mathrm{~N} / / \mathrm{min}$ )

Figure 7 shows the fluid movement is in upwards direction and recirculates in the region of top surface and there was no dead zone when two opposed tuyeres were placed at half radii (Case $\mathrm{C}$ ). Figure 8 shows the flow pattern when two tuyeres were vertically placed at half radii (Case D). Contrary to Case C, the fluid



(b) visualized

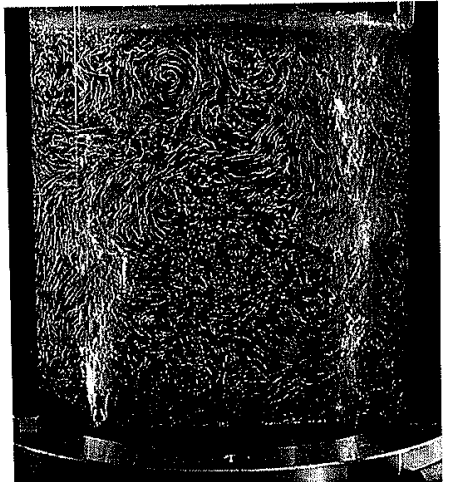

Fig. 7. Predicted and visualized flow patterns as two tuyeres were opposite place at half radii in the ladle. (Case C, argon flowrate $6 \mathrm{~N} l / \mathrm{min}$ )

movement is in downwards direction near the sidewalls of the ladle. The total average velocity seemed to be smaller and there was a dead zone at the corner between the side and bottom wall. In addition, Fig. 11 shows that the velocity at the free surface in Case $C$ seems to be more homogenous than that of Case $\mathrm{D}$, which will be in favor of preventing splashing, spitting and nonmetallic inclusion from entrapping into molten steel, as well as produces good mixing in the ladle (as discussed later).

Figures 9(a) and 9(b) show the predicted and visualized flow patterns respectively when argon gas was injected through three tuyeres. The flow pattern of Case $\mathrm{E}$ is similar to that of Case C. In this case the flow near the sidewall is stronger than that of Case $\mathrm{C}$, but the average velocity is less.

Figures 10(a) and 10(b) show the predicted and visualized flow patterns respectively at the main vertical plane when argon gas was injected through four tuyeres located at half radii in the ladle (Case F). Figure 10 shows two big and strong cloud of recirculations near the regions of sidewalls were formed which are very similar to the case of center blowing (as seen in Fig. 3). Due to 




(b) visualized

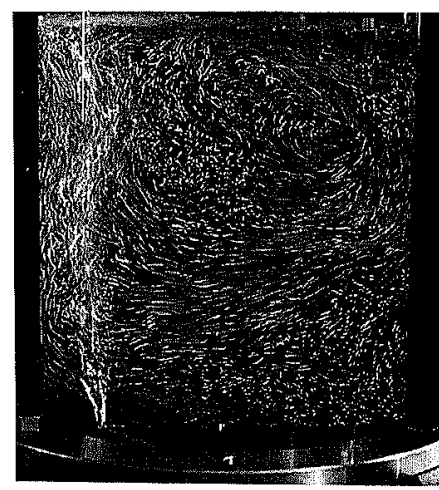

Fig. 8. Predicted and visualized flow patterns as two tuyeres were vertically placed at half radii in the ladle. (Case $\mathrm{D}$, argon flowrate $6 \mathrm{~N} l / \mathrm{min}$ )

the symmetric arrangement of tuyeres, there was almost no angular velocity in the ladle (as seen in Fig. 12).

The similarity of flow pattern between predicted and visualized shows that the present mathematical model is capable of describing the fluid flow in argon-stirred ladle with multi-tuyere. However, there are some small distinctions because the flow in the argon-stirred ladle is turbulent and cannot keep stable all the time while it has been taken into account stable state in the calculations.

\subsection{The Effect of Tracer Adding Position on Mixing}

A complete and consistent description for mixing phenomena in argon-stirred ladle with multi-tuyere has not been reported at present. The present study may be the first study on the mixing phenomena in argon-stirred ladles with multi-tuyere by numerical analysis. Figure 13(a) shows the predicted and measured values of mixing time in the ladle with various arrangement of tuyeres when the tracer was added at the center of the surface, whereas Fig. 13(b) shows the predicted and mean measured mixing time for three tracer adding positions.

It can be seen that the position of tracer addition has

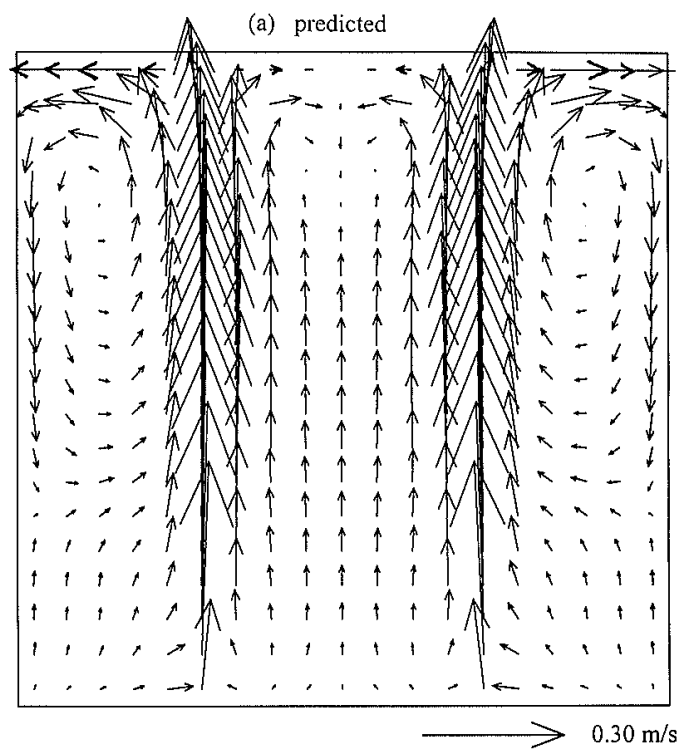

(b) visualized

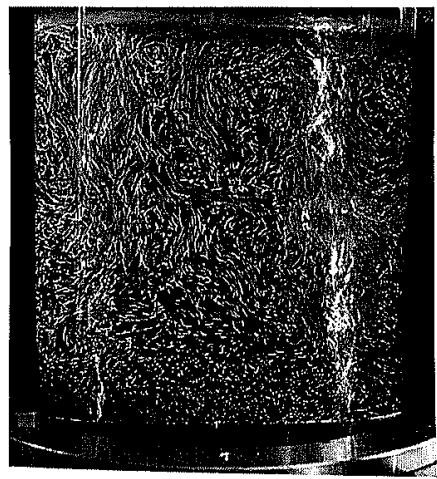

Fig. 9. Predicted and visualized flow patterns as three tuyeres were place at half radii in the ladle. (Case E, argon flowrate $6 \mathrm{~N} l / \mathrm{min}$ )

a great effect on mixing in the ladle, especially in Case $A$ and Case $F$ which are much more sensitive due to almost no angular mixing in the ladle. In Case B and Case $\mathrm{D}$, mixing time becomes insensitive to the tracer adding position due to the larger angular velocity. The predicted mixing time is on good agreement with the measured values.

\subsection{The Effect of Configuration of Tuyeres on Mixing}

For the sake of comparison, the mean value of predicted and measured mixing time were obtained from three different tracer adding positions for different arrangement of tuyeres as shown in Fig. 14. Figure clearly indicates that the shortest mixing time is obtained in the case of single tuyere placed off center (Case B). Due to this reason, most of steelmaking shops still work with this type of arrangement. However, our main aim is to achieve the gentle but rapid mixing to promote metal/slag interaction, and to avoid splashing, spitting and entrapping of non-metallic inclusion into bulk phase. To satisfy all these purposes, multi-bubbling is needed. On the basis of measured and predicted values as it can be 
seen in Fig. 14, Case $\mathrm{C}$ was found to be the best arrangement, namely, two tuyeres are opposite placed at half radii in the ladle, Case $F$ and Case $D$ are reasonable and Case $\mathrm{E}$ was found to be the worst. These results can be explained by their characteristics of fluid flow and mixing mechanism in the ladle. In Case $\mathrm{D}$, a dead zone was found and mean velocity is smaller than that of Case $\mathrm{C}$ (as seen in Figs. 7 and 8). In Case D, since the two

(a) predicted

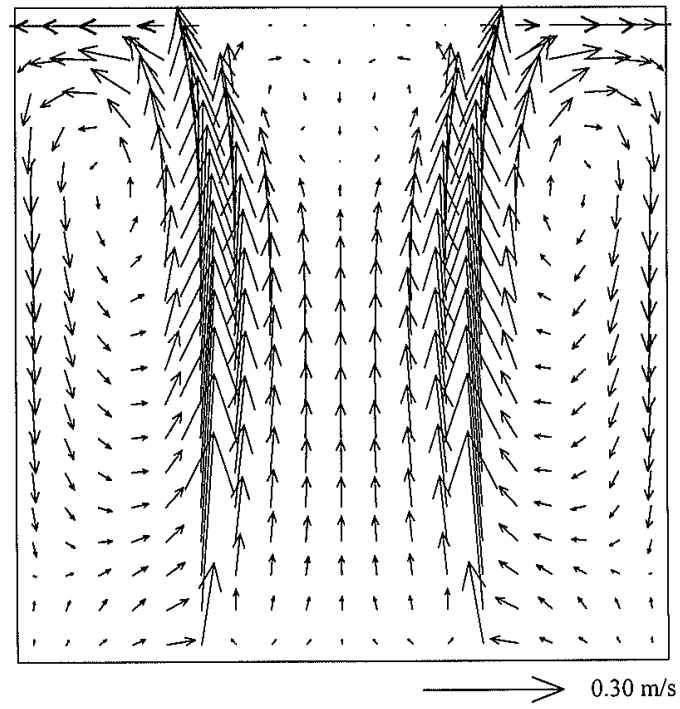

(b) visualized

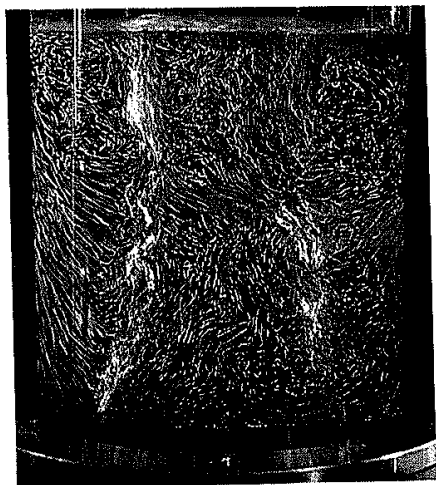

Fig. 10. Predicted and visualized flow patterns as four tuyeres were placed at half radii in the ladle. (Case $\mathrm{F}$, argon flowrate $6 \mathrm{~N} / / \mathrm{min}$ )

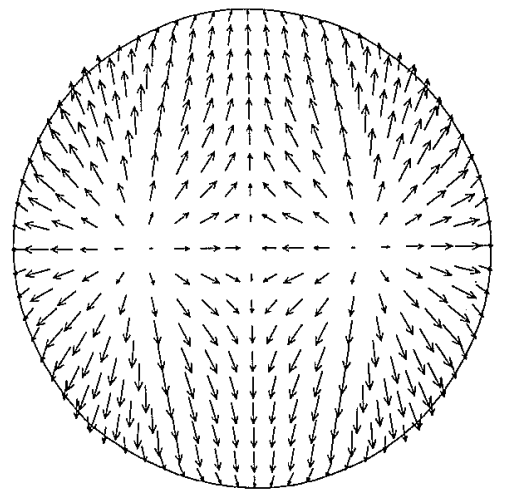

(a) Case $\mathrm{C}$ bubble streams are closer than in Case $\mathrm{C}$, the interaction between them is high, therefore it is not favorable for the whole flow development (as seen in Fig. 11). For the purpose of gentle blowing, Case D also loses its advantage compared with Case C. So, the arrangement of Case C is better than Case D.

As Fig. 10 indicated, in Case F, the bulk motion is very strong, although the angular velocity is very small. Increase in diffusive components is the resultant of increase the interaction and shearing action among the bubbles streams. As it is well known that the mixing process in ladles is controlled by both bulk convection and eddy diffusion. In Case $F$, the tuyere configuration can be considered better because of short time of mixing. Of course, in this case the materials consumption of tuyeres will be more.

Good agreement between calculated mixing time and measured data shows that the mixing behavior in argon-stirred ladles with single or multi-tuyere can be properly described by using the present mathematical model.

\subsection{The Effect of Gas Flowrate on Mixing}

The tendency for predicted mixing time to change with the injected gas flowrate with different configuration of tuyere is shown in Fig. 15. In general, it can be concluded that the mixing time decreases with increasing gas flowrate but the effect is not impressive.

\subsection{A Correlation for Mixing Time}

In the stirring system, mixing greatly depends on the intensity of agitation, so the specific stirring power has been used to express the relationship with mixing time. Nakanishi et al. ${ }^{22)}$ has proposed the first correlation $\tau_{m}=800 \varepsilon^{-0.40}$ according to measurements in the argonstirred ladle for RH and ASEA-SKF and $\tau_{m}=800 \varepsilon^{-0.40}$ $N^{1 / 3}$ for combined blowing converters. ${ }^{35)}$ In the present study, a relationship was found to be similar to the latter type which was determined to describe the mixing time in the argon-stirred ladle with single or multi-tuyere. Figure 16 shows the relationship between the predicted mixing time with respect to Case $B$, Case $C$ and Case $E$ and $\varepsilon_{m}^{-0.33} N^{0.33}$ or $\varepsilon_{m}^{-0.40} N^{0.33}$. Since the mixing time in gas-stirred ladle is proportional to $Q^{-0.33}$ and the buoyancy power is the main part contributing to the mixing, ${ }^{1-2,14,25,26,35)}$ the order of $\varepsilon_{m}$ should be close to

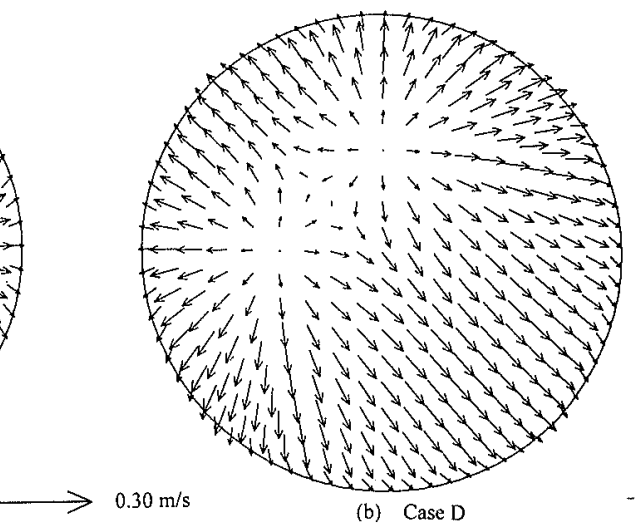

Fig. 11. Predicted flow patterns at free surface in the ladle for Case $\mathrm{C}$ and Case $\mathrm{D}$. (argon flowrate $6 \mathrm{~N} l / \mathrm{min}$ ) 


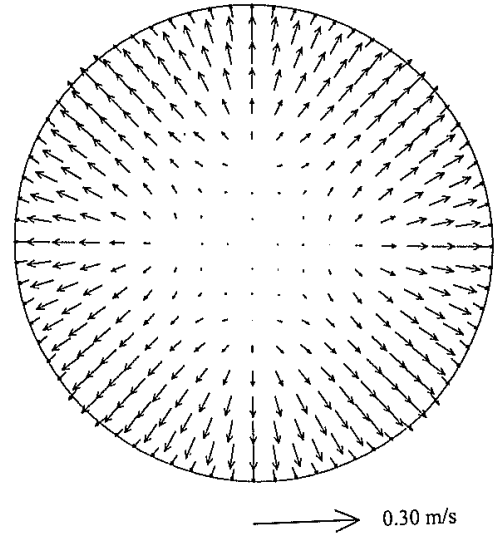

Fig. 12. Predicted flow pattern at free surface in the ladle for Case F. (argon flowrate $6 \mathrm{~N} l / \mathrm{min}$ )
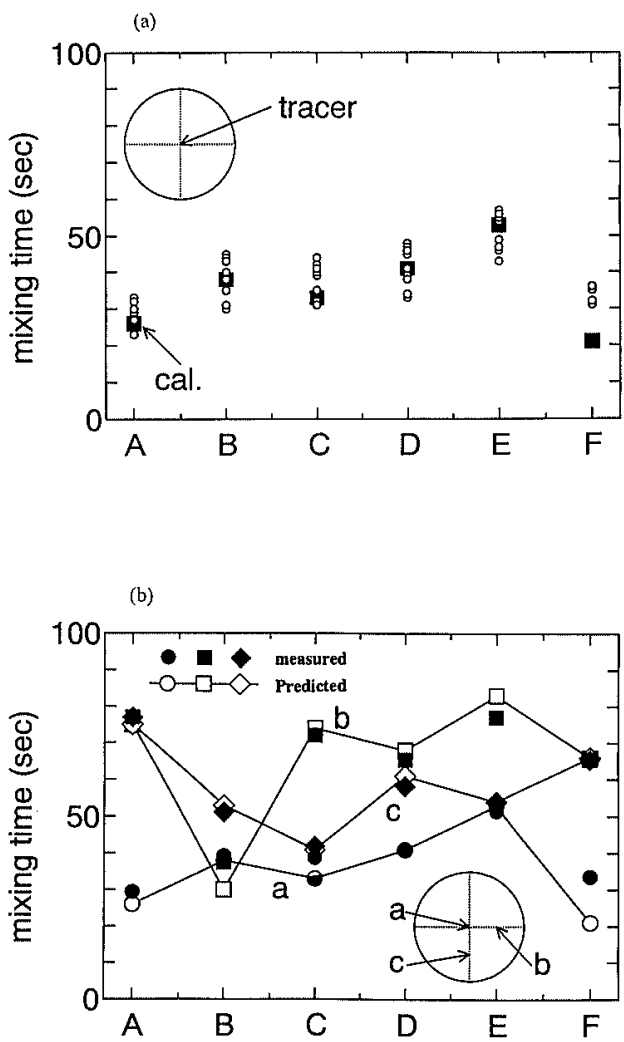

Fig. 13. Predicted and measured mixing time for each tracer adding position. (gas flowrate $6 \mathrm{~N} / / \mathrm{min}$ )

-0.33 which can also be seen in Fig. 16. Therefore, the correlation for mixing time can be written as follows:

$$
\tau_{m}=8.52 \varepsilon_{m}^{-0.33} N^{0.33} \quad(N=1-3)
$$

where

$$
\varepsilon_{m}=\varepsilon_{b}+\eta \varepsilon_{k} \text { and } \eta=0.1
$$

$\varepsilon_{b}$ the buoyancy power is given by ${ }^{36}$ ):

$$
\varepsilon_{b}=\frac{1484 Q T_{b}}{\rho_{l} \pi D^{2} H}\left[2 \ln (1+0.097 H)-\frac{H}{10.3+H}\right]
$$

$\varepsilon_{k}$ the kinetic energy of injected gas can be given as:

$$
\varepsilon_{k}=\frac{32 \rho_{g} Q^{3}}{\pi^{3} d^{4} D^{2} H \rho_{l}}
$$

The unit of $\varepsilon_{m}$ is standard, namely watt $/ \mathrm{kg}$. If it is used



Fig. 14. Relationship between tuyere configuration and $95 \%$ bulk mixing time. (gas flowrate $6 \mathrm{~N} l / \mathrm{min}$ )

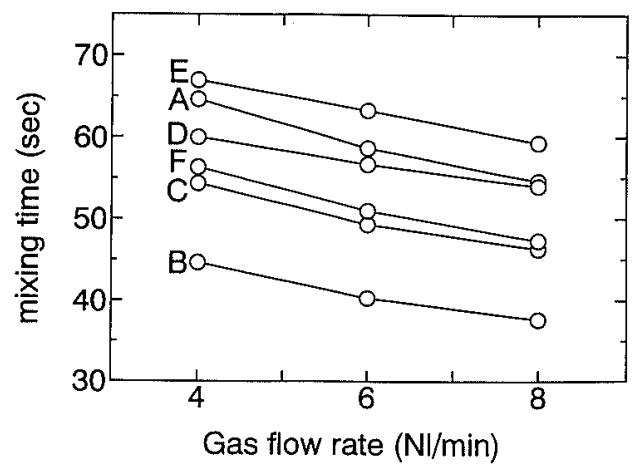

Fig. 15. Effect of gas flowrate on mixing time.

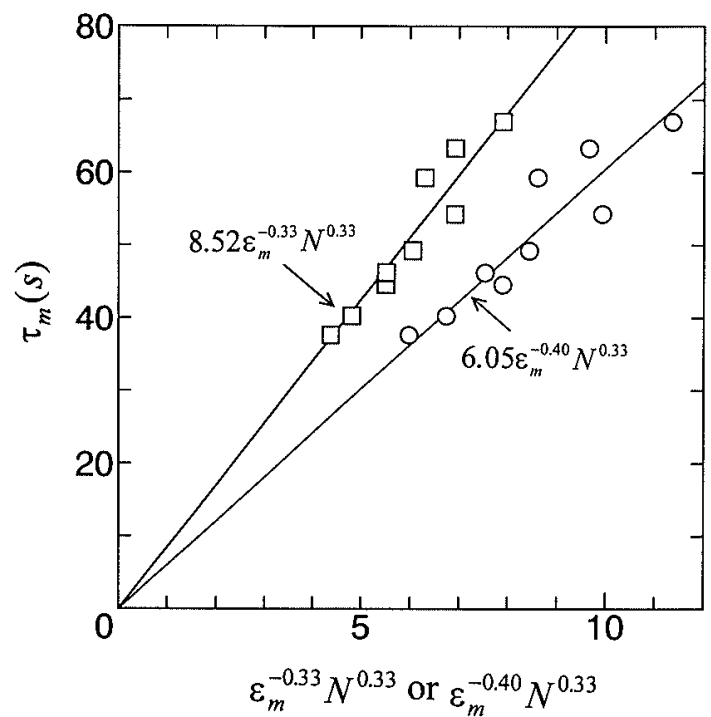

Fig. 16. Mixing time as a function of stirring power and number of tuyere.

the same as Nakanishi's, namely watt/t, the coefficients of present correlation will increase ten times. However, there is still a big difference compared with Nakanishi's which may be attributed to that of vessel size and the consideration of contribution of kinetic energy of injected gas to the mixing.

\section{Conclusions}

The fluid flow and mixing phenomena in argon-stirred ladles with multi-tuyere were studied with the help of physical modeling and mathematical modeling. Considering the effects of tracer adding position, tuyere 
arrangement and injected gas flowrate on mixing, a proper configuration of tuyeres for gentle blowing but rapid mixing has been proposed. On the basis of above results and discussions, the following conclusion can be drawn.

(1) The configuration of tuyeres has a great influence on the fluid flow and mixing in the ladles. The asymmetric arrangements are in favor of increasing the angular momentum whereas in the case of symmetric arrangement, there is almost no angular motion in the ladle.

(2) Mixing time is greatly influenced by tracer adding position, especially in the case of exactly symmetric arrangement of tuyeres.

(3) It is possible to obtain gentle blowing but rapid mixing in the ladle by using multiple bubbling. Two tuyeres opposite placed at half radii in the ladle shows the best arrangement to realize the various purposes of secondary refining.

(4) Generally, mixing time decreases with increasing gas flowrate, but the effect is not great.

(5) The empirical relationship for mixing time in the ladle can be given by $\tau_{m}=8.52 \varepsilon_{m}^{-0.33} N^{0.33}(N=1-3)$.

(6) The predicted results by using present mathematical model are on very good agreement with measured results.

\section{Acknowledgments}

The principal author wishes to express his sincere appreciation to Professor T. Fuwa for his valuable guidance, constant encouragement and valuable support throughout this work. The author is grateful to Dr. K. Umezawa, Dr. T. Matsumiya and Dr. M. Yano of Nippon Steel Corporation for support of this work and fruitful discussions.

\section{Nomenclature}

$\begin{aligned} C: & \text { Tracer concentration } \\ C_{1}, C_{2}, C_{\mu}: & \text { Empirical turbulent constants } \\ D: & \text { Vessel diameter } \\ G_{k}: & \text { Generation term of turbulent kinetic } \\ & \text { energy } \\ g: & \text { Gravitational acceleration } \\ H: & \text { Bath height } \\ k: & \text { Kinetic energy of turbulence } \\ p: & \text { Pressure } \\ Q: & \text { Gas flowrate at NTP } \\ S_{c}: & \text { Laminar Schmidt number } \\ S_{c t}: & \text { Turbulent Schmidt number } \\ t: & \text { Time } \\ T_{b}: & \text { Bath temperature } \\ u_{i}: & \text { Velocity component in } i \text { direction; } i=1-3 \\ x_{i}: & \text { Coordinate; } i=1-3\end{aligned}$

Greek symbols

$\alpha:$ Volume fraction of gas in the plume zone

$\varepsilon:$ Dissipation rate of turbulent kinetic energy

$\varepsilon_{m}:$ Specific mixing power

$\tau_{m}$ : Mixing time

$\Gamma_{\text {eff }}$ : Effective mass diffusion coefficient

$\mu_{l}$ : Molecular viscosity

$$
\begin{aligned}
\mu_{t}: & \text { Turbulent viscosity } \\
\mu_{\mathrm{eff}}: & \text { Effective viscosity } \\
\rho: & \text { Density of fluid } \\
\rho_{g}: & \text { Density of gas } \\
\rho_{l}: & \text { Density of liquid } \\
\eta: & \text { Efficiencies }(0.1)
\end{aligned}
$$

\section{REFERENCES}

1) M. Sano and K. Mori: Trans. Iron Steel Inst. Jpn., 20 (1980), 668.

2) T. C. Hsiao, T. Lehner and B. Kjellberg: Scand. J. Metall., 9 (1980), 105.

3) Y. Sahai and R. I. L. Guthrie: Metall. Trans., 13B (1982), 193.

4) K.-H. Tache, H.-G. Schubert, D. J. Weber and K. Schwerdtfeger: Metall. Trans., 16B (1985), 263.

5) A. H. Castillejos and J. K. Brimacombe: Metall. Trans., 18B (1987), 659.

6) G. G. Krishna Murthy, A. Ghosh and S. P. Mehrotra: Metall. Trans., 19B (1988), 885 .

7) Y. Y. Sheng and G. A. Irons: Metall. Trans., 23B (1992), 779.

8) J. Szekely, H. J. Wang and K. M. Kiser: Metall. Trans., 7B (1976), 287.

9) T. DebRoy, A. H. Majumdar and D. B. Spalding; J. Met., (1981), $11,42$.

10) J. H. Grevet, J. Szekely and N. EI-Kaddah: Int. J. Heat Mass Transfer, 25 (1982), 487.

11) Y. Sahai and R. I. L. Guthrie: Metall. Trans., 13B (1982), 203.

12) F. Oeters, H.-C. Dromer and J. Kepura: SCANINJECT III, Lulea, Sweden, (1983), paper 7.

13) S. T. Johansen and T. A. Engh: Scand. J. Metall., 16B (1985), 83.

14) D. Mazumdar and R. I. L. Guthrie: Metall. Trans., 16B (1985), 83.

15) I. Sawada and T. Ohashi: Tetsu-to-Hagané, 73 (1987), 669.

16) S. T. Johansen and F. Boyan: Metall. Trans., 19B (1988), 775.

17) J. Mietz and F. Oeters: Steel Res., 60 (1989), 387.

18) A. H. Castillejos, M. E. Salcudean and J. K. Brimacombe: Metall. Trans., 20B (1988), 603.

19) S. Joo, R. I. L. Guthrie and K. Kamal: Steelmaking Proc., ISS-AIME, 72 (1989), 517.

20) H. Turkoglu and B. Farouk: ISIJ Int., 31 (1991), 1371.

21) S.-I. Chung, Y. H. Shin and J.-K. Yoon: ISIJ Int., 32 (1992), 1287.

22) K. Nakanishi, T. Fujiii and J. Szekely: Ironmaking Steelmaking, 2 (1975), 193.

23) O. Haida, T. Emi, S. Yamada and F. Sudo: SCANINJECT II, Lulea, Sweden, (1980), paper 20.

24) N. EI-Kaddah and J. Szekely: Ironmaking Steelmaking, 8 (1981), 269.

25) S. Asai, T. Okamoto, J.-C He and I. Muchi: Trans. Iron Steel Inst. Jpn., 23 (1983), 43.

26) M. Sano and K. Mori: Trans. Iron Steel Inst. Jpn., 23 (1983), 169.

27) Y. Ohga, S. Tanigụchi and J. Kikuchi: Tetsu-to-Hagané, 71 (1985), S897.

28) U. P. Sinha and M. J. McNallan: Metall. Trans., 16B (1985), 850

29) D. Mazumdar and R. I. L. Guthrie: Metall. Trans., 17B (1986), 725.

30) S.-H Kim and R. J. Fruehan: Metall. Trans., 18B (1987), 381.

31) J. Mietz and F. Oeters: Steel Res., 59 (1988), 52.

32) G. G. Krishna Murthy, S. P. Mehrotra and A. Ghosh: Metall. Trans., 19B (1988), 839.

33) B. E. Launder and D. B. Spalding: Comput. Meth. Appl. Mech. Eng., (1974), No. 3, 269.

34) M. Y. Zhu, I. Sawada and T. C. Hsiao: to be published in ISIJ Int

35) K. Nakanishi, K. Saito and T. Nozaki: Steelmaking Conf. ISS-AIME, PA., 65 (1982), 101.

36) M. P. Schwarz: ISIJ Int., 31 (1991), 947. 